\section{Prevalence of cataract in the Speedwell Cardiovascular Study: a cross-sectional survey of men aged 65-83}

\begin{abstract}
Aims To ascertain the prevalence of cataract in a representative group of men who have been followed since 1979 for cardiovascular disease.
\end{abstract}

Methods Of 2348 men aged 45-63 recruited in 1979 to the Speedwell Cardiovascular Study, 1420 were alive and willing to take part in further studies in 1997. They were sent a questionnaire about their eye health and invited to an ophthalmological examination at Bristol Eye Hospital. Cataract was graded using the Lens Opacities Classification System III (LOCS III) method. Results Of the 1420 men, 26 died before they could be examined. Out of the remaining 1394 men, 949 presented for examination and full information was available for 936. Some information about eye health was obtainable for 394 men and 51 were not contactable. The prevalence of cataract increased with age and 36 men $\mathbf{3} .8 \%)$ had had previous cataract surgery in either or both eyes. Of the remaining 903 men with no previous history of cataract surgery, cortical cataract was present in the right eye of 75 men $(8.3 \%)$, nuclear (opalescence) in $128(\mathbf{1 4 . 2 \%})$ and posterior subcapsular in 15 (1.7\%). Five men $(0.6 \%)$ had visual acuity of $6 / 60$ or worse attributable to cataract in the right eye and $232(25 \%)$ had visual acuity in one or both eyes of $6 / 24$ or less at least partially attributable to cataract. There was no association between social class and the presence of cataract.

Conclusions The prevalence of cataract in a representative cohort of men followed since 1979 for cardiovascular disease was comparable to that previously reported in the
N Stocks ${ }^{1}$, R Patel $^{2}$, J Sparrow ${ }^{3}$ and

G Davey-Smith ${ }^{4}$

UK and is consistent with studies from around the world. It appears that substantial amounts of visual loss, attributable to cataract, are present in men. Further studies establishing the reasons for this should be undertaken.

Eye (2002) 16, 275-280. DOI: 10.1038/

sj/eye/6700106

Keywords: cataract; prevalence; social class; epidemiology; cardiovascular

\section{Introduction}

Age-related cataract is the main cause of reversible blindness in the UK. There are no proven preventive measures and the only form of treatment is surgical extraction and insertion of an intraocular lens. The scope of the problem is large, in the UK there were 153000 National Health Service (NHS) operations for cataract performed in 1997/98 and the recent 'Action on Cataracts' government initiative has set a target of 250000 NHS cataract operations by $2003 .{ }^{1}$ Surveys reporting the prevalence of cataract in the UK have been undertaken previously. ${ }^{2-5}$ The Framingham study in the US has reported data from a cohort followed for cardiovascular disease, ${ }^{6}$ but no similar studies in the UK have examined such a group.

Cohorts provide advantages for researchers examining associations between eye disease and risk factors because of the longitudinal nature of the data. Such prospective studies, with measurement of risk factors before the development of the condition, are preferable to cross-sectional studies, particularly if behaviours or risk factors change with time. They also allow an accurate assessment of
'Department of General Practice

Adelaide University, Australia

${ }^{2}$ Department of Social Medicine

University of Bristol, UK

${ }^{3}$ Bristol Eye Hospital Bristol, UK

${ }^{4}$ Department of Social Medicine

University of Bristol, UK

Correspondence:

Dr N Stocks

Senior Lecturer

Department of General

Practice

Adelaide University

SA 5005

Australia

Tel: +61 883033462

Fax: +61 883033511

E-mail nigel.stocks@

adelaide.edu.au 
prevalence because with reasonable follow-up they still form a representative cross-sectional sample of the atrisk population. The participation in a cohort study may allow individuals to be examined who would not have been recruited into a cross-sectional study due to ill-health, social isolation or failure to maintain contact with the basis for sampling-such as electoral registers or general practices. Selection bias may thus be lower in cohort follow-up studies than in standard prevalence surveys.

\section{Methods}

\section{Study population}

The Speedwell Study involved recruitment of 2348 men aged 45-63 in 1979, representing a 92\% response rate from a population-based sample of men of this age living in the Speedwell area of Bristol. ${ }^{7}$ These men were examined four times over the period 1979-1991 (Phases 1-4). Repeat detailed assessments of cardiovascular disease, blood pressure, serum lipids, haemostatic factors (including fibrinogen), alcohol intake, psychosocial factors, immunology, anthropometry and health-related behaviours were made.

In 1995 all the men who were alive from the original cohort were asked to participate in a follow-up study about stroke; 1507 men returned a questionnaire and were thus eligible to be included in the Speedwell Eye Study. However by 1997 eighty seven men from this group had died, so only 1420 were sent questionnaires about their eye health and asked to participate in a study examining risk factors for age-related maculopathy and cataract. A concurrent study concerning cognition and memory ran in parallel to the eye study.

\section{Procedures}

The men were invited to attend an eye examination at the Bristol Eye Hospital (BEH). If they did not have transport a taxi was arranged. The men were welcomed and a description of the procedures given. This included the possibility of adverse reactions to the eye drops used. Permission to pass on medical details to their GP, if required, was also requested if conditions requiring follow-up were detected. If they were in agreement they signed a consent form. Ethical approval for the study was obtained from The United Bristol Healthcare and Frenchay NHS Research Ethics Committees.

A single investigator (RP) examined all but 32 of the participants. A brief history was taken concerning past ocular history and allergies to any medication. Unaided and corrected vision with habitual correction, or spectacles if worn, was then tested at 4 metres using a self-illuminated Bailey and Lovie LogMAR chart with the room lights off. Beginning with the right eye the test was started with the first line that could be read without any mistakes and continued until all five letters on one line were misread (forced choice). If they had not brought their spectacles retinoscopy was performed. An amsler chart test was administered, with the habitual reading correction in place, if used, to detect the presence of scotoma and/or metamorphopsia. The patient's spectacles were then placed on a focimeter, the lenses measured and recorded in minus cylinder form.

The subject was moved to a slit lamp and the anterior chamber depth assessed using the van Hericks technique. The iris was also examined for clip lenses, as these were deemed unsuitable for dilation. If the angle was deep or moderate then one drop of tropicamide $1 \%$ and one drop of phenylephrine $2.5 \%$ were instilled to achieve maximal mydriasis. During the period of dilation the subject was asked detailed questions about their past medical and ocular history.

On the slit lamp the eyelids and lid margins were observed for any lesions and the conjunctiva examined for pingeculae and ptyrigia. The Lens Opacities Classification System II (LOCS III) method for cataract assessment was followed. ${ }^{8}$ Nuclear opalescence and brunescence were assessed using a narrow slit beam and a comparison made with six standardised photographs and a decimalised scale from 0.1 to 6.9 used. An assessment of the anterior/posterior subcapsular area was made using retroillumination. Comparisons were made between any lesion and 10 standard transparencies on a decimalised scale from 0.1 to 5.9. Similarly the cortical area was assessed and compared with a standard set of five transparencies. A clinical assessment of the macular was made with a Volk 78D lens and the optic disc to cup ratio measured. Finally a standard intraocular pressure measurement was made with a Goldmann applanation tonometer.

\section{Data handling}

All data were entered into an Access database and checked for outliers and missing values. Data were analysed using STATA. Logistic regression analysis was used to examine the relationship between the presence or absence of a cataract and social class. Cutoff points for LOCS III grading of 1.9 were used for cortical cataract, 2.9 for nuclear, 1.9 for PSC and self reported cataract operation to define the presence or 
Table 1 Social class in 1979 by age group at the time of examination in the Speedwell Eye Study (1997-1999)

\begin{tabular}{llllll}
\hline Age group & \multicolumn{5}{c}{ Social Class } \\
\cline { 2 - 6 } & $\begin{array}{l}\text { I and II } \\
\text { Professional and } \\
\text { managerial }\end{array}$ & $\begin{array}{l}\text { IIIa } \\
\text { Skilled non-manual } \\
\text { workers }\end{array}$ & $\begin{array}{l}\text { IIIb } \\
\text { Skilled } \\
\text { manual workers }\end{array}$ & $\begin{array}{l}\text { IV and V } \\
\text { Semi-skilled and } \\
\text { unskilled manual workers }\end{array}$ & Total \\
\hline $65-69$ & 91 & 51 & 159 & 49 & $350(37.4 \%)$ \\
$70-74$ & 85 & 53 & 149 & 51 & $338(36.1 \%)$ \\
$75+$ & 57 & 38 & 118 & 35 & $248(26.5 \%)$ \\
Total & $233(24.8 \%)$ & $142(15.2 \%)$ & $426(45.5 \%)$ & $135(14.4 \%)$ & 936 \\
\hline
\end{tabular}

absence of cataract. Both unadjusted and age-adjusted analysis were performed.

\section{Results}

Of the 1420 men who were still part of the Speedwell study, 182 declined both the eye examination and memory test, 51 were not contactable and 26 men died before they could attend for examination. A total of 949 men presented for examination, 144 returned the questionnaire only and 68 attended the memory study only. Of the 949 who attended the $\mathrm{BEH}$, seven refused to have their pupils dilated and six had contraindications such as a shallow anterior chamber or iris clip lenses. Full data were therefore available for 936 men; their age distribution, by their reported social class in 1979, is given in Table 1.

\section{Prevalence of cataract}

Table 2 presents the number of cortical, nuclear opalescence, nuclear colour and posterior subcapsular (PSC) cataracts found in the right eye, by age group, using the LOCS III grading. Individuals could have more than one type of cataract so an individual could contribute to more than one column total. To illustrate how many men had multiple cataracts; of 103 (11\% of all men) who had either a nuclear colour or nuclear opalescence cataract of LOCS III grading of 4 or more, $82(8.8 \%$ of all men) had minimal cortical or PSC cataract (LOCS grading < 1.9), 19 (2.0\% of all men) had either a PSC or cortical cataract (LOCS grading $>1.9$ ) and two $(0.2 \%$ of all men) had all three types.

The severity of cataract varied by age and Figure 1 demonstrates the effect of increasing age on the grade of cataract in the right eye. Again individuals can have a combination of cataract types with different degrees of severity.

Visual acuity by cataract type is presented in Table 3 for the right eye. Examining combinations of cataract type, in the eight men with 6/60 vision or worse in the right eye attributable to cataract, we found that three

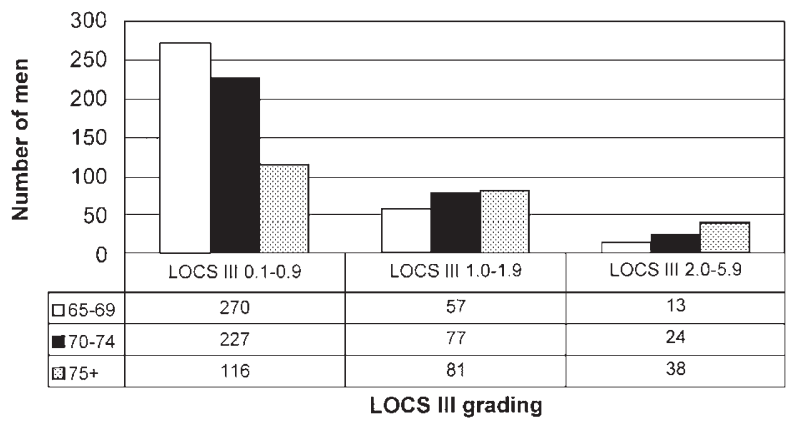

Figure 1 LOCS III grading of right cortical cataract by age group. Speedwell Eye Study (1997-1999).

Table 2 Prevalence of any cataract in the right eye by age group (\% in age group or total) $n=903$. Speedwell Eye Study (1997-1999)

\begin{tabular}{|c|c|c|c|c|c|}
\hline Age group & $\begin{array}{c}\text { Cortical } \\
\text { LOCS III >1.9 }\end{array}$ & $\begin{array}{c}\text { Nuclear (opalescence) } \\
\text { LOCS III }>2.9\end{array}$ & $\begin{array}{l}\text { Nuclear (colour) } \\
\text { LOCKS III >2.9 }\end{array}$ & $\begin{array}{c}\text { PSC } \\
\text { LOCKS III }>1.9\end{array}$ & Any cataract \\
\hline $\begin{array}{l}65-69 \\
n=340\end{array}$ & $13(3.8 \%)$ & $20(5.9 \%)$ & $65(19.1 \%)$ & $1(0.3 \%)$ & $75(22 \%)$ \\
\hline $\begin{array}{l}70-74 \\
n=328\end{array}$ & $24(7.3 \%)$ & $42(12.8 \%)$ & $128(39.0 \%)$ & $4(1.2 \%)$ & $150(45.7 \%)$ \\
\hline $\begin{array}{l}75+ \\
n=235\end{array}$ & $38(16.2 \%)$ & $66(28.0 \%)$ & $149(63.4 \%)$ & $10(4.2 \%)$ & $173(73.6 \%)$ \\
\hline $\begin{array}{l}\text { Total } \\
n=903\end{array}$ & $75(8.3 \%)$ & $128(14.2 \%)$ & $342(37.9 \%)$ & $15(1.7 \%)$ & $398(44.1 \%)$ \\
\hline
\end{tabular}


Table 3 Visual acuity by cataract type in the right eye. Speedwell Eye Study (1997-1999) $n=903$

\begin{tabular}{|c|c|c|c|c|c|c|c|}
\hline Visual acuity & $\begin{array}{l}\text { Cortical cataract } \\
\text { LOCS III }>1.9\end{array}$ & $\begin{array}{c}\text { Nuclear } \\
\text { (opalescence) } \\
\text { LOCS } \text { III }>2.9\end{array}$ & $\begin{array}{l}\text { Nuclear } \text { (colour) } \\
\text { LOCS } \text { III }>2.9\end{array}$ & $\begin{array}{c}\text { PSC } \\
\text { LOCS III }>1.9\end{array}$ & $\begin{array}{c}\text { Any } \\
\text { cataract }\end{array}$ & $\begin{array}{c}\text { No } \\
\text { cataract }\end{array}$ & Total \\
\hline $6 / 6$ or better & $11(3.8 \%)$ & $24(8.2 \%)$ & $83(28.4 \%)$ & $2(0.7 \%)$ & $96(32.9 \%)$ & $196(67.1 \%)$ & 292 \\
\hline $6 / 12$ & $45(8.9 \%)$ & $73(14.5 \%)$ & $206(40.9 \%)$ & $6(1.2 \%)$ & $236(46.8 \%)$ & $268(53.2 \%)$ & 504 \\
\hline $6 / 24$ & $15(18.3 \%)$ & $21(25.6 \%)$ & $38(46.3 \%)$ & $4(4.9 \%)$ & $50(61.0 \%)$ & $32(39.0 \%)$ & 82 \\
\hline $6 / 48$ & $1(5.9 \%)$ & $5(29.4 \%)$ & $8(47.1 \%)$ & $2(11.8 \%)$ & $9(52.9 \%)$ & $8(47.1 \%)$ & 17 \\
\hline $6 / 60$ or worse & $3(37.5 \%)$ & $5(62.5 \%)^{\mathrm{a}}$ & $7(87.5 \%)^{\mathrm{b}}$ & $1(12.5 \%)$ & $7(87.5 \%)$ & $1(12.5 \%)$ & 8 \\
\hline Total $n=903$ & $75(8.3 \%)$ & $128(14.2 \%)$ & $342(37.9 \%)$ & $15(1.7 \%)$ & $398(44.1 \%)$ & $505(55.9 \%)$ & 903 \\
\hline
\end{tabular}

aPoor vision due to AMD in one case.

${ }^{b}$ Poor vision due to AMD in one case and retinal detachment in one.

had a cortical cataract $>1.9$ combined with nuclear (colour and opalescence) $>3.9$, one man had PSC $>1.9$ combined with nuclear (colour and opalescence $>3.9$ ) and one man with a nuclear cataract (colour and opalescence $>3.9$ ) but with no cortical or PSC cataract $>1.9$. The rest had other combinations of lesser severity; their poor vision was probably due to retinal disease, these are identified in Table 3.

\section{Prevalence of past cataract surgery}

Aphakia was present in one right eye. Pseudophakia was present in 32/936 (3.4\%) right eyes, 9/350 (2.6\%) in the 65-69 age group, 10/338 (2.9\%) in those aged $70-74$ and $13 / 248(5.2 \%)$ in those 75 or older. It was present in either or both eyes in 36/936 (3.9\%) men. We also had information about men who did not attend for examination because 144/471 (31\%) had returned a questionnaire that included questions about cataract surgery or had attended the memory study $68 / 471(14 \%)$. We were also able to review the general practice records of those men registered at one of four general practices in Bristol and we contacted by telephone a further 69 men who had moved away from Bristol. Using these strategies we obtained information about eye disease and cataract surgery on all but $51 / 471(11 \%)$ men (4\% of the remaining cohort of 1420 men). With this information we were able to identify an additional 42 men who had undergone cataract surgery on one or both eyes. The prevalence of past cataract surgery for this larger group was therefore $5.8 \%$ (79/1369). The prevalence of cataract surgery in the non-responding group was $10.0 \%$ $(42 / 420)$ compared to the group examined at the research clinic of $3.9 \%(36 / 936)$.

\section{Relationship between social class and the presence of cataract}

There was no statistically significant trend in the association between social class and the presence or absence of any form of cataract, and this lack of association remained after adjusting for age (Table 4). There was however a significant association with selfreported cataract operation for social classes I and IIcompared to social classes IV and V combined-that persisted after adjustment for age.

\section{Discussion}

Many studies have examined the prevalence of cataract around the world. In the UK since the early 1980s there have been four cross-sectional surveys of eye disease $^{2-5}$ and two that have dealt with minority groups. ${ }^{9,10}$ Uniquely the Speedwell Eye study examined a group of men who have been part of a prospective study of heart disease and stroke. Relationships between the development of cataract and risk factors for cardiovascular disease, such as, high blood pressure, smoking, diabetes, high body mass index and hypertriglyceridemia have been demonstrated previously. ${ }^{6,11-14}$ Like the Framingham and Beaver Dam studies in the USA the Speedwell Eye study will enable the evaluation of risk factors for cataract using longitudinal data as well as reporting the crosssectional results for major eye diseases in the UK, cataract and age-related maculopathy.

The men in this study formed a sub-group of a representative sample of the male population living in the Speedwell area of Bristol in 1979. At the time of recruitment to this study many of the original cohort had died and some had declined further participation after one or more phases of the original study. Some had moved to other areas of Bristol or towns and villages nearby. Others had moved much further away and although contactable were not able to attend for the eye examination. A small group were lost to follow-up because they had not informed us of a change of address. Any cohort will be subject to losses over time. The Speedwell study achieved response rates of over $90 \%$ in the early phases of the study and only $13 \%$ of those alive from Phase 1 had withdrawn 
Table 4 Binary logistic regression. Odds ratio (95\% confidence interval) of having a cataract in social classes I and II, IIIa and IIIb compared to social classes IV and V combined

\begin{tabular}{lccccc}
\hline Social class & $\begin{array}{c}\text { Cortical cataract } \\
\text { (ORs) } n=903\end{array}$ & $\begin{array}{c}\text { Nuclear opalescence } \\
\text { cataract } \\
\text { (ORs) } n=903\end{array}$ & $\begin{array}{c}\text { Nuclear colour } \\
\text { cataract } \\
\text { (ORs) } n=903\end{array}$ & $\begin{array}{c}\text { Posterior subcapsular } \\
\text { cataract } \\
\text { (ORs) } n=903\end{array}$ & $\begin{array}{c}\text { Self reported cataract } \\
\text { (ORs) } n=1130\end{array}$ \\
\hline I and II & $0.94(0.41-2.21)$ & $0.81(0.45-1.44)$ & $0.74(0.48-1.15)$ & $0.85(0.14-5.14)$ & $0.39(0.17-0.91)^{*}$ \\
IIIa & $P=0.887$ & $P=0.472$ & $P=0.186$ & $P=0.857$ & $P=0.028$ \\
& $2.02(0.87-4.67)$ & $0.61(0.31-1.21)$ & $0.87(0.54-1.43)$ & $2.40(0.46-12.62)$ & $0.84(0.37-1.86)$ \\
IIIb & $P=0.102$ & $P=0.158$ & $P=0.591$ & $P=0.300$ & $P=0.661$ \\
& $1.15(0.53-2.47)$ & $0.70(0.491-1.20)$ & $0.77(0.52-1.16)$ & $0.77(0.15-4.03)$ & $0.70(0.36-1.35)$ \\
IV and V & $P=0.723$ & $P=0.192$ & $P=0.210$ & $P=0.759$ & $P=0.288$ \\
\hline
\end{tabular}

All OR were non significant except for self reported cataract social class I and II. Speedwell Eye Study (1997-1999).

*Significant after adjustment for age (OR $=0.4095 \% \mathrm{CI}(0.17-0.93) P=0.033)$.

from the Speedwell study and were therefore not eligible to be recruited by us. Because the results could be biased if those who did not attend for examination and did not return the postal questionnaire had more or less eye disease than those who did, we contacted virtually all the non-responders by phone or checked their medical records. The finding that the prevalence of past cataract surgery was much greater in nonresponders indicates the importance of contacting nonresponders in any cross-sectional survey. We relied on self-report to obtain some information. Self-reporting of cataract has been examined in other studies which have suggested that clinical determinations are necessary, ${ }^{15}$ however we asked about cataract surgery which would be more accurately reported than a question concerning whether a sight-limiting cataract had ever been diagnosed. We also verified self-report with information from medical records for men still registered with one of four practices in Bristol. GP records in the UK should be viewed as a reliable source of information about cataract surgery, unless it was undertaken overseas. The overall figure for the cohort $(6 \%)$ is comparable to figures of $5.8 \%^{4}$ and $10 \% 5$ reported for groups with an older age range and including women.

In our study we used the LOCS III system which has been validated in other studies. It is different from the Wisconsin system used in the Beaver Dam (BD) ${ }^{16}$ and Blue Mountain Eye Study (BMES) ${ }^{17}$ and that used for the Framingham study. It is therefore difficult to compare the prevalence of lens opacities and cataract in these studies as different criteria and definitions were used. Even in studies where comparisons have been made using standardized grading regimes and where real differences due to race or risk factors that could affect interpretation have been minimised, inconsistent results have been obtained in older age groups ( $>65$ years). However comparing our study with the BD and BMES studies it is evident that the trends are similar for all, with an increasing prevalence of early and late cataract with increasing age (see Figure 1) and with cortical and nuclear cataract being the predominant forms.

Unlike some studies we did not demonstrate a consistent relationship between the presence of cataracts and socio-economic position. ${ }^{18}$ These studies have mainly been in the US. We used broad categories for social class that had been recorded in 1979.

Changes in social circumstances may explain the absence of any social gradient in our cataract results but it may also be due to better access to eye care, compared to their US equivalents, for men in lower socio-economic groups. The finding that men in social classes I and II had fewer cataract operations than men in social class IV and V was unexpected and may be due to chance (multiple testing) alone.

We assessed visual acuity with the person wearing their own spectacles, not the potential best vision. We therefore assessed the degree of visual impairment at the time of examination. We found that a large number of men had 'habitually' poor visual acuity at least partially attributable to cataract. Although some of these men might benefit from changes to their glasses prescription, 232 (25\%) had visual acuity in one or both eyes of $6 / 24$ or less. With the reinstatement of free eye tests for the over $60 \mathrm{~s}$, at least one barrier to older people seeking regular eye tests has been removed. ${ }^{19}$ Anecdotally it was apparent that many of the men were not concerned with their visual loss, many no longer drove and whilst cataract may have affected their vision they had not sought help from their optician or GP. This reinforces the limitations of relying on visual acuity to assess the need for cataract surgery ${ }^{20}$ and the importance of examining quality of life issues. ${ }^{21}$ In developing countries the uptake of cataract surgery, when freely available, can still be low 
because individuals fear surgery or do not have the time. ${ }^{22}$ In Australia lack of knowledge about eye disease was very common, ${ }^{23}$ particularly in those with lower levels of education and this could explain the reluctance of some to access eye health services. In the UK it has been suggested that the failure to integrate vision checks for the elderly into primary care, a reluctance to add to waiting lists and uncertainties about treatment and outcome may be to blame. ${ }^{5}$

This study presents the results of a cross-sectional eye survey in a group of men who have had serial assessments of risk factors for heart disease since 1979. The prevalence of past cataract surgery was comparable to that reported in previous eye studies in the UK and consistent with studies from around the world. An increasing prevalence of early and late cataract with increasing age was found, with cortical and nuclear cataract being the predominant forms. Although we did not demonstrate a relationship between the presence of cataract with social class, it appears that in this group of predominately working class men, that substantial amounts of visual loss, attributable to cataract, are present in the community. Further studies establishing the reasons for this should be undertaken.

\section{Acknowledgements}

We would like to thank Research into Ageing and the National Eye Research Centre for funding this research and the Bristol Eye Hospital for providing a suitable area for performing the eye examinations. We would also like to acknowledge the assistance of Heather McElroy for her statistical help in the preparation of this paper.

\section{References}

1 NHS Executive. Action on Cataracts. Good Practice Guidelines. Department of Health: PO Box 77, London, SE1 6XH 2000.

2 Deane JS, Hall AB, Thompson JR, Rosenthal AR. Prevalence of lenticular abnormalities in a populationbased study: Oxford Clinical Cataract Grading in the Melton Eye Study. Ophthal Epidemiol 1997; 4: 195-206.

3 Gibson JM, Rosenthal AR, Lavery J. A study of the prevalence of eye disease in the elderly in an English community. Trans Ophthalmol Soc UK 1985; 104: 196-203.

4 Wormald RPL. Visual problems in the elderly population and implications for services. BMJ 1992; 304: 1226-1229.

5 Reidy A, Minassian DC, Vafidis G, Joseph J, Farrow S, $\mathrm{Wu} \mathrm{J}$ et al. Prevalence of serious eye disease and visual impairment in a north London population: population based, cross sectional study. BMJ 1998; 316: 1643-1646.
6 Kahn H, Leibowitz H, Ganley JP, Kini MM, Colton T, Nickerson RS, Dawber TR. The Framingham Eye Study II: association of ophthalmic pathology with single variables previously measured in the Framingham Heart Study. Am J Epidemiol 1977; 106: 33-41.

7 The Caerphilly and Speedwell Collaborative Group. Caerphilly and Speedwell collaborative heart disease studies. J Epidemiol Commun Health 1984; 38: 259-262.

8 Chylack LT Jr, Wolfe JK, Singer DM, Leske MC, Bullimore MA, Bailey IL et al. The Lens Opacities Classification System III. The Longitudinal Study of Cataract Study Group. Arch Ophthalmol 1993; 111: 831836.

9 Das BN, Thompson JR, Patel R, Rosenthal AR. The prevalence of eye disease in Leicester: a comparison of adults of Asian and European descent. J Royal Soc Med 1994; 87: 219-222.

10 Gray PJ. The prevalence of eye disease in elderly Bengalis in Tower Hamlets. J Royal Soc Med 1996; 89: 23-26.

11 Jahn C, Janke M, Winowski H, von Bergman K, Leiss O, Hockwin O. Identification of metabolic risk factors for posterior subcapsular cataract. Ophthalmic Res 1986; 18: 112-116.

12 Klein BE, Klein R, Linton KL, Franke T. Cigarette smoking and lens opacities: the Beaver Dam Eye Study. Am J Prevent Med 1993; 9: 27-30.

13 West SK, Valmadrid CT. Epidemiology of risk factors for age-related cataract. Surv Ophthalmol 1995; 39: 323-334.

14 Glynn RJ, Christen WG, Manson JE, Bernheimer J, Hennekens $\mathrm{CH}$. Body mass index. An independent predictor of cataract. Arch Ophthalmol 1995; 113: 11311137.

15 Christen WG, Glynn RJ, Seddon JM, Manson JE, Buring JE, Hennekens $\mathrm{CH}$. Confirmation of self-reported cataract in the Physicians' Health Study. Ophthal Epidemiol 1994; 1: 85-91.

16 Klein BE, Klein R, Linton KL. Prevalence of age-related lens opacities in a population. The Beaver Dam Eye Study. Ophthalmology 1992; 99: 546-552.

17 Mitchell P, Cumming RG, Attebo K, Panchapakesan J. Prevalence of cataract in Australia: the Blue Mountains eye study. Ophthalmology 1997; 104: 581-588.

18 Klein R, Klein BE, Jensen SC, Moss SE, Cruickshanks KJ. The relation of socioeconomic factors to age-related cataract, maculopathy, and impaired vision. The Beaver Dam Eye Study. Ophthalmology 1994; 101: 1969-1979.

19 van der Pols JC, Thompson JR, Bates CJ, Prentice A, Finch S. Is the frequency of having an eye test associated with socioeconomic factors? A national cross sectional study in British elderly. J. Epidemiol Commun Health 1999, 53: 737-738.

20 Mordue M, Parkin DW. Visual impairment is not enough to assess need for treatment. BMJ 1998; 317: 1319-1320.

21 The Royal College of Ophthalmologists. Guidelines for Cataract Surgery. Royal College of Ophthalmologists: 17 Cornwall Terrace, London, NW1 4QW, 1995.

22 Snellingen T, Shrestha BR, Gharti MP, Shrestha JK, Upadhyay MP, Pokhrel RP. Socioeconomic barriers to cataract surgery in Nepal: the South Asian cataract management study. Br J Ophthalmol 1998; 82: 1424-1428.

23 Attebo K, Mitchell P, Cumming R, Smith W. Knowledge and beliefs about common eye diseases. Aust NZ J Ophthalmol 1997; 25: 283-287. 